\title{
Multiple Layers Lens Capsule True Exfoliation in Patient with Primary Angle Closure Glaucoma
}

\author{
Xiongwu Zhou $\cdot$ Guigang Li $\cdot$ Hong Zhang $\cdot$ \\ Xinyu Li $\cdot$ Yang Guan $\cdot$ Liu Bing
}

To view enhanced content go to www.ophthalmology-open.com

Received: June 12, 2012 / Published online: August 21, 2012

(c) The Author(s) 2012. This article is published with open access at Springerlink.com

\section{ABSTRACT}

Introduction: True exfoliation of lens capsule is a relatively rare disorder that has a thin, fluttering membrane in the anterior chamber, mainly located in the pupil area, which is believed to have split from the anterior lens capsule.

Case Report: The authors present here a patient with true exfoliation and primary angle closure glaucoma in both eyes, the ultrastructure of one eye revealed that the delaminated membrane was composed of more than two layers in itself.

X. Zhou · G. Li $(\varangle) \cdot$ H. Zhang $\cdot$ X. Li

Department of Ophthalmology, Tongji Hospital, Tongji Medical College, Huazhong University of Science and Technology, 1095 Jiefang Dadao, Wuhan 430022, Hubei, People's Republic of China e-mail: guigli@163.com

Y. Guan · L. Bing

Department of Ultrastructural Pathology, Tongji Medical College, Huazhong University of Science and Technology, Wuhan 430030, Hubei,

People's Republic of China

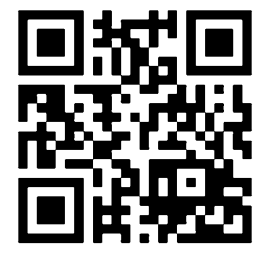

Enhanced content for this article is available on the journal web site: www.ophthalmology-open.com
Conclusion: Lens capsule true exfoliation could happen in patient with primary angle closure glaucoma, with more than two layers in itself.

Keywords: Glaucoma; Lens capsule; True exfoliation; Ultrasound biomicroscopy; Ultrastructure

\section{INTRODUCTION}

True exfoliation of the lens capsule is a relatively rare disorder, which was first reported by Elschnig et al. [1] in 1922. The clinical manifestation has been described as a thin, fluttering membrane in the anterior chamber, mainly located in the pupil area, which is believed to have split from the anterior lens capsule. The pathogenesis of this disorder is not clear; traditionally it has been attributed to infrared radiation, exposure to ultraviolet light, inflammation, trauma, and idiopathic causes. Another risk factor is aging [1-16]. At present little is known about the pathology of the membrane splitting from the lens capsule, and the relationship between this disorder and glaucoma is ambiguous. Here the authors describe a case of bilateral true exfoliation of the lens capsule with primary angle closure glaucoma. 


\section{CASE REPORT}

\section{General Information}

The authors present a 74-year-old female farmer from a mountain village of Hubei province, China, with no history of excessive exposure to heat or surgery, no family history of this disorder or glaucoma. This study was carried out following informed consent from the patient, and the tissue was handled according to the Declaration of Helsinki.

\section{Clinical Examination}

The best corrected visual acuity was finger counting at $0.05 \mathrm{~m}$ in the right eye and $12 / 20$ in the left eye, the vision loss of both eyes
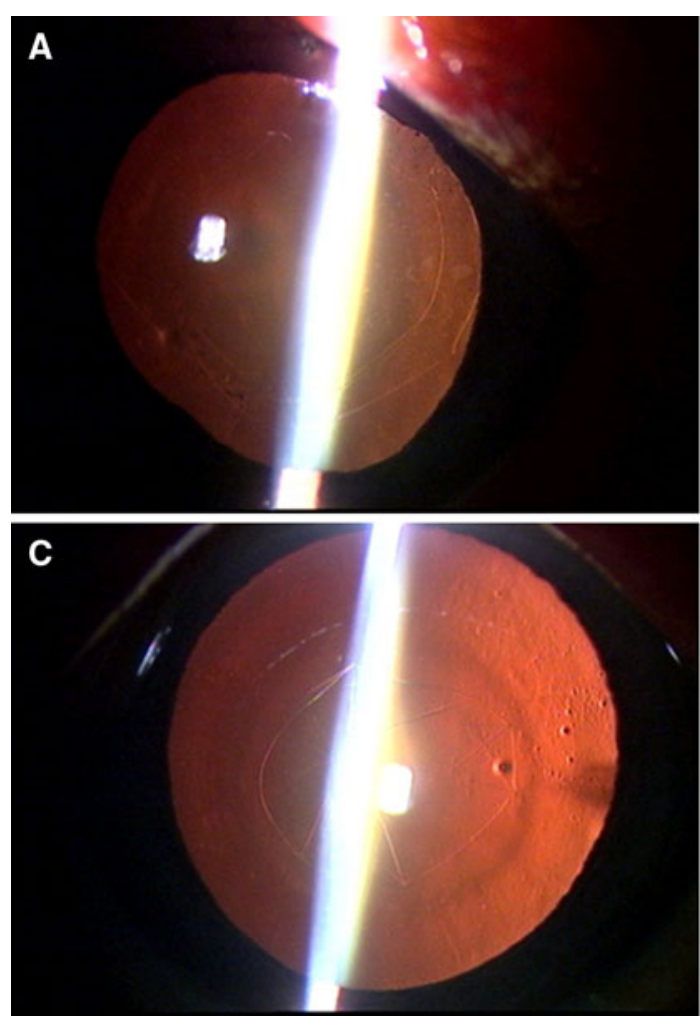

Fig. 1 Lens capsule true exfoliation under slit lamp microscopy. Clear, diaphanous capsular membranes were seen in both anterior chambers superior to the central anterior lens capsule (slit-lamp). The right eye, with a could not be corrected with glasses. The intraocular pressure was $60 \mathrm{mmHg}$ in the right eye and $17 \mathrm{mmHg}$ in the left eye. Slitlamp examination revealed that the right cornea was edematous and the anterior chambers of both eyes were shallow. The right pupil was ellipse and fixed, dilated to $7 \mathrm{~mm}$, the diameter of the left pupil was $4 \mathrm{~mm}$. Both lenses had moderate opacity and this was more serious in the right eye. The cup/disc ratio was 0.5 in the right eye and 0.3 in the left eye. Clear, diaphanous membranes were seen in both anterior chambers (Fig. 1). The capsular peeling was limited to the central anterior capsule. There was no iris transillumination, pseudoexfoliation, or phacodonesis, which may be accompanied with lens capsule true exfoliation. Gonioscopy of the left eye revealed

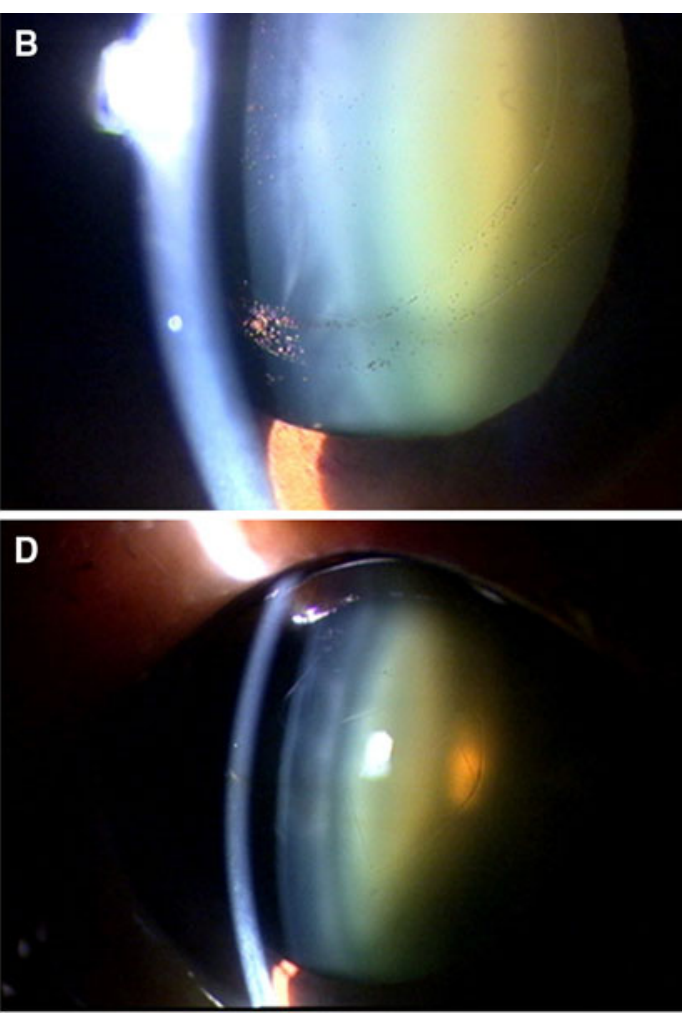

dilated pupil as a result of an attack of primary angle closure glaucoma (a, b). The left eye, with pupil was dilated for phacoemulsification cataract extraction $(\mathbf{c}, \mathbf{d})$ 

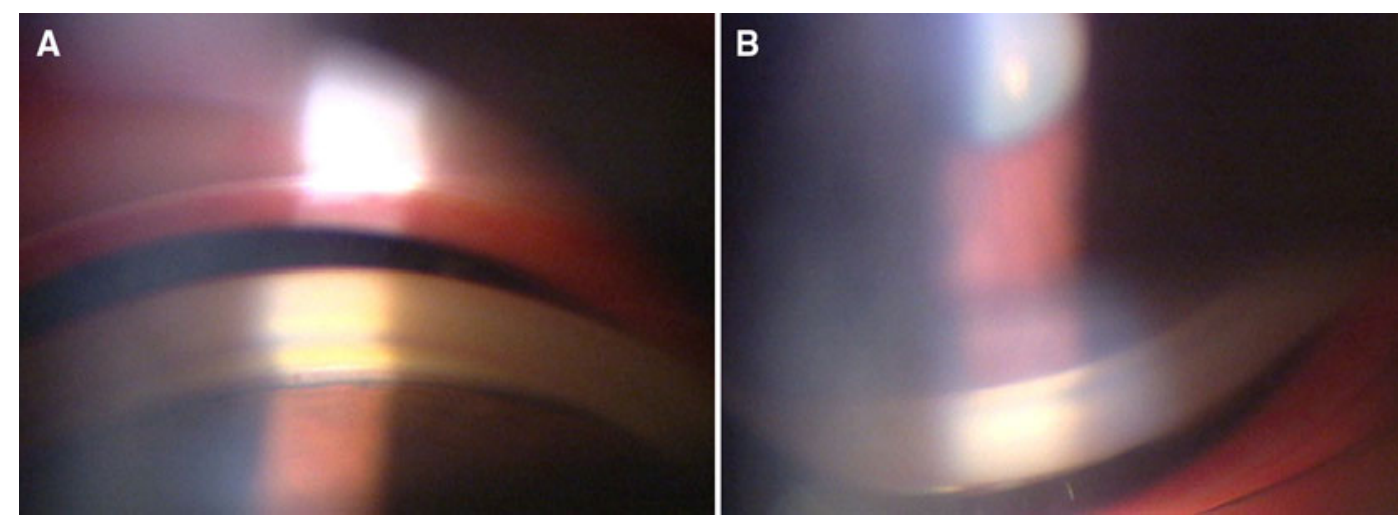

Fig. 2 Closed anterior chamber angle under gonioscopy. Gonioscopy of the left eye revealed a narrow but open angle at 6 o'clock (a) and a closed angle at 12 o'clock (b)

a narrow open angle at 6 o'clock and a closed angle at 12 o'clock (Fig. 2). Ultrasound biomicroscopy (UBM,SW-2100; Tianjin Suowei Electronic Technology Co., Ltd., China) demonstrated a membrane inserting into the anterior chamber from the surface of the anterior lens capsule (Fig. 3).

\section{Diagnosis and Treatment}

The major diagnosis was primary angle closure glaucoma in the right eye and eclipse period in the left eye. The authors prescribed mannitol, $1 \%$ pilocarpine and $2 \%$ mikelan eye drops, after which the intraocular pressure of the right eye dropped to $17 \mathrm{mmHg}$ within $24 \mathrm{~h}$, the corneal edema had decreased under the slit-lamp microscope. After a few days, the patient underwent a non eventful trabeculectomy in her right eye, and a cataract phacoemulsification with intraocular lens implantation in her left eye. The split membrane and the central anterior capsule of the left eye was extracted separately and fixed with $2.5 \%$ glutaraldehyde immediately after surgery, submitted for ultrastructural pathologic examination (transmission electron microscopy [TEM]: FEI Tecnai G2 12; FEI, Hillsboro, OR, USA).

\section{RESULTS}

\section{Outcome of the Surgery}

The best corrected visual acuity of the right eye returned to $10 / 20$ and the left eye to $16 / 20$ within a 3-months follow-up period. Because the cornea endothelial cell density of the right eye decreased to 657 cells $/ \mathrm{mm}^{2}$, the lens of the right eye received no further surgery. The intraocular pressure of both eyes was in the normal range, which was between 11 and $21 \mathrm{mmHg}$, and the right corneal edema subsided in the follow-up period of 12 months.

\section{Light Microscopy}

Light microscopy (Fig. 4) revealed that the membrane superior to the anterior lens capsule appeared as one layer in some parts and separated into two or three layers in others. The anterior lens capsule was always one layer, with normal lens epithelium. 

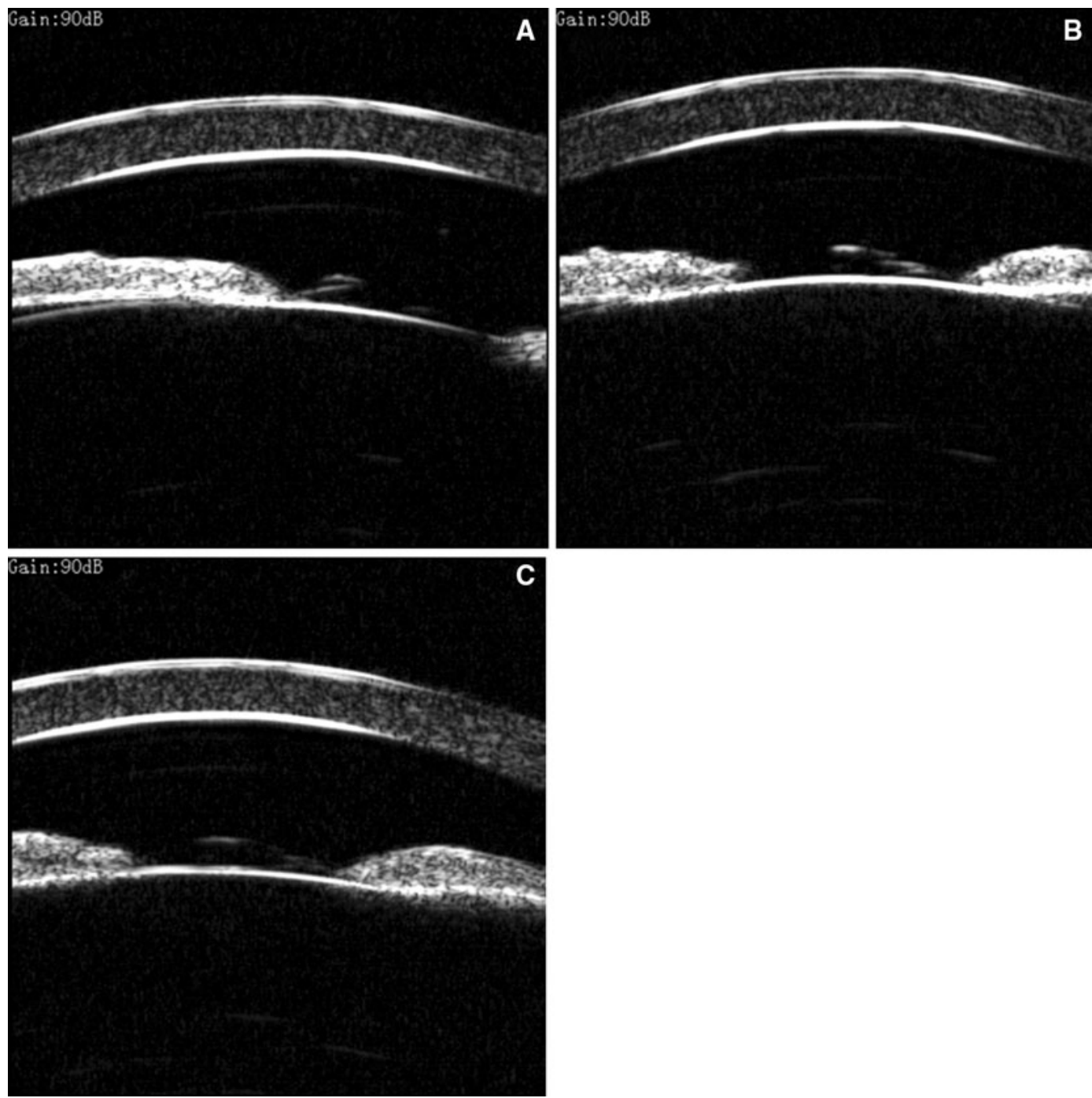

Fig. 3 Lens capsule true exfoliation under ultrasound biomicroscopy. Ultrasound biomicroscopy (UBM,SW-2100) demonstrating a membrane inserting into the anterior chamber from the anterior lens capsule in the left eye (a-c)

\section{Transmission Electron Microscopy}

TEM revealed an interesting phenomenon that has never been described before. Figure 5 shows that the so-called split membrane is composed of more than two layers in itself. With a total thickness of $12.5-18 \mu \mathrm{m}$, each layer was approx-imately $5-6 \mu \mathrm{m}$, composed of homogeneous granular material that was arranged in a linear or band pattern. A cleavage plane was present where the layers had separated. Figure 6 shows that the anterior lens capsule is normal, with a thickness of $16 \mu \mathrm{m}$ and normal epithelial cells.

\section{DISCUSSION}

\section{The Relationship Between Glaucoma and True Exfoliation}

Unlike pseudoexfoliation, a causative factor of open angle glaucoma, the relationship between true exfoliation and glaucoma is ambiguous. 

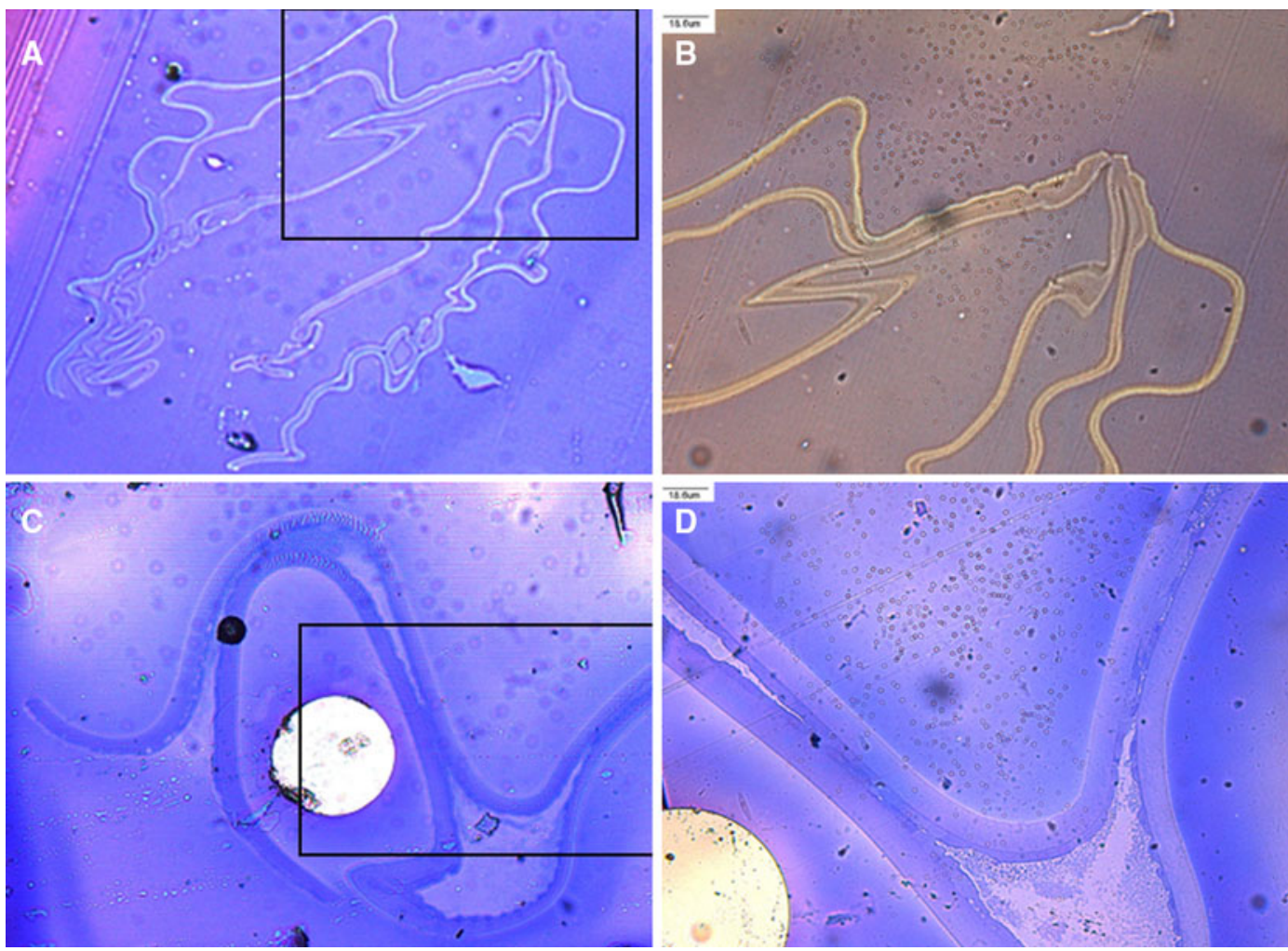

Fig. 4 Lens capsule true exfoliation and remaining capsule under light microscopy. Light microscopy of the membranes superior to the anterior lens capsule $(\mathbf{a}, \mathbf{b})$ and anterior lens capsule (c, d), (b, d) is the amplification of part of $(\mathbf{a}, \mathbf{c})$, respectively. The membrane superior to the anterior lens capsule united into one layer in some parts and separated into two or three layers in others.

However, these two disorders may occur in the same eye simultaneously. The patient reported here was found to have primary angle closure glaucoma as her primary problem, with true exfoliation as an incidental finding. True exfoliation was first distinguished from pseudoexfoliation by Dvorak-Theobald [17] in 1953, in which fibrillar material may deposit on the lens, zonules, and trabecular meshwork, which can lead to open angle glaucoma [18-21]. What is more, true exfoliation and pseudoexfoliation of the anterior lens capsule had once been found simultaneously in the same eye [16].
The anterior lens capsule was always one layer, with normal lens epithelium. Most importantly, no step was found in the anterior lens capsule, with a diameter of $5 \mathrm{~mm}$, which was wider than that of the split area of the anterior lens capsule; this may means that the so-called split membrane superior to the anterior lens capsule is not really generated from the anterior lens capsule, but from the aqueous humor

\section{The Cause and Origin of True Exfoliation}

The cause of true exfoliation remains obscure, mainly because this disorder has not been duplicated in an animal model. According to the information from clinical data, these processes possibly have an underlying causality from intense infrared radiation exposure. Traditionally it has been thought to be caused by heat or infrared-related changes in the anterior capsule. It has also been associated with trauma, intraocular inflammation and idiopathic causes [1-16]. Age-related changes in the lens may also play a role in true 


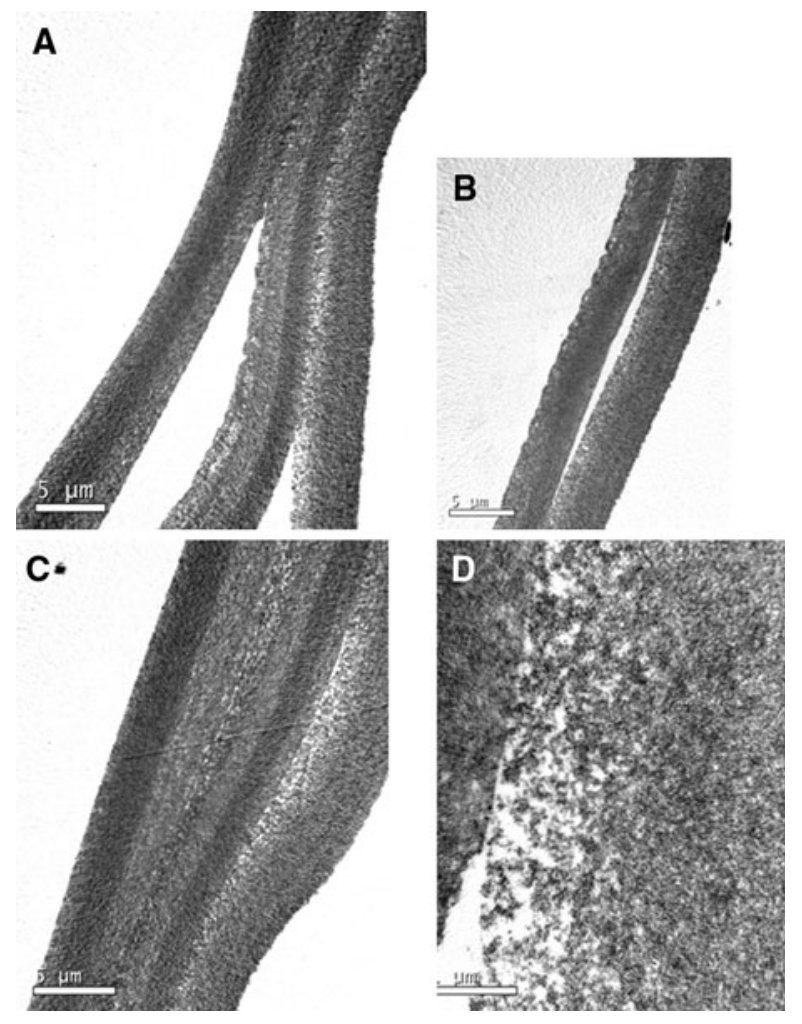

Fig. 5 Lens capsule true exfoliation under transmission electron microscopy. Transmission electron microscopy of the membrane superior to the anterior capsule revealed that the so-called split membrane is composed of two or three layers in itself $(\mathbf{a}, \mathbf{b})$. With a total thickness of $12.5-18 \mu \mathrm{m}$, each layer is approximately 5-6 $\mu \mathrm{m}(\mathbf{a}-\mathbf{c})$, composed of homogeneous granular material that was arranged in a linear or band pattern. A cleavage plane was present where the layers had separated $(\mathbf{d})$, which was the amplification of part of (a)

exfoliation of the lens because idiopathic true exfoliation in the absence of history appears more common in older patients $[4,6-8,12]$.

Anderson and van Bockxmeer [14] and Seland [22] found that the electrophoretic patterns of the delaminated capsule were different from age-matched normal capsules, and hypothesized that capsular protein abnormality might play a role. The possibility of heat-activated proteolysis has also been suggested as a cause of capsular delamination; delamination of the anterior lamella might
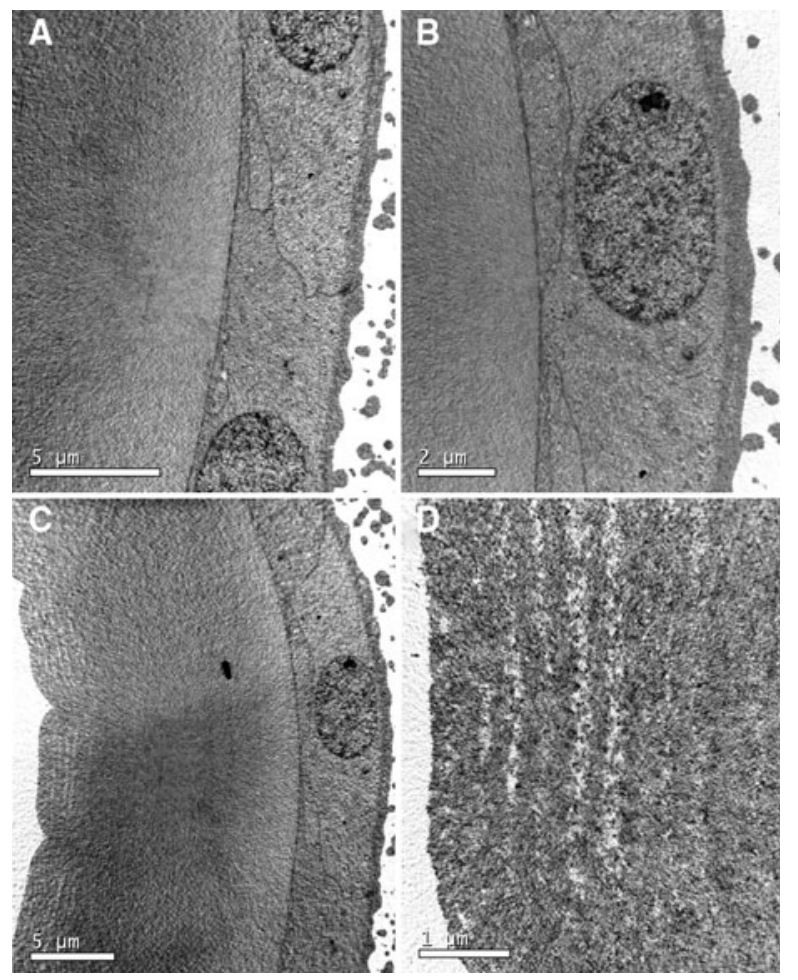

Fig. 6 The remaining capsule and epithelial cells under transmission electron microscopy. Transmission electron microscopy of the anterior lens capsule revealed a normal thickness of $16 \mu \mathrm{m}$ and normal lens epithelial cells $(\mathbf{a}-\mathbf{c})$, composed of homogeneous granular material that was arranged in a linear or band pattern; (d) is the amplification of part of (c)

develop as a result of degeneration of the fibrillar constituents of the membrane or damage to the interfibrillar cement [2]. Brodrick and Tate [5] noted an ultrastructural change in the epithelium of the delaminated capsule, and suggested that their finding of degranulated and dilated endoplasmic reticulum with clumped nuclear chromatin might indicate a cellular abnormality as a potential underlying cause of the scrolling.

In this patient, there was no history of exposure to excessive heat, intense infrared radiation, uveitis, or trauma. This should be grouped into idiopathic true exfoliation in the left eye, although the authors could not ignore the fact 
that the attack of angle closure glaucoma induced inflammation. The thickness, ultrastructure and lens epithelium of the remaining anterior capsule was higher than that of the age-matched normal capsules as reported previously, which should be approximately $8 \mu \mathrm{m}$ for 65 -year-old humans [22-24]. More interestingly, the delaminated membrane separated into two or three layers in itself, with a thickness of 5-6 $\mu \mathrm{m}$ in each layer, and a total thickness of $12.5-18 \mu \mathrm{m}$.

\section{CONCLUSION}

Lens capsule true exfoliation could occur in patients with primary angle closure glaucoma, with more than two layers in itself. The thickness and electron density of the remaining capsule under TEM is relatively normal when compared with age-matched capsules from senile cataract. There was no abnormality in the lens epithelial cell either.

\section{ACKNOWLEDGMENTS}

Zhiqi Chen, MD, Ruilin Wang MD, Fuzhi Deng, and Juan Huang assisted in the surgery and pathobiology process. Dr. G. Li is the guarantor for this article, and takes responsibility for the integrity of the work as a whole. This research was funded by the Science Foundation of Hubei Province, conferred to X.L. (no. 2008CDB214).

\section{Conflict of interest. None.}

Open Access. This article is distributed under the terms of the Creative Commons Attribution Noncommercial License which permits any noncommercial use, distribution, and reproduction in any medium, provided the original author(s) and source are credited.

\section{REFERENCES}

1. Elschnig A. Ablosung der zonula lamella bei Glasblaserm I. Klin Monatsbl Augenheilkd. 1922; 69:732-4 (In German).

2. Callahan A, Klien BA. Thermal detachment of the anterior lamella of the anterior lens capsule. Arch Ophthalmol. 1958;59:73-80.

3. Burde RM, Bresnick G, Uhrhammer J. True exfoliation of the lens capsule: an electron microscope study. Arch Ophthalmol. 1969;82: 651-3.

4. Fiore PM, Shingleton BJ. Senile lens exfoliation. JAMA. 1990;264:2755.

5. Brodrick JD, Tate GW Jr. Capsular delamination (true exfoliation) of the lens. Report of a case. Arch Ophthalmol. 1979;97:1693-8.

6. Radda TM, Klemen UM. Idiopathische echte Exfoliation. Klin Monatsbl Augenheilkd. 1982; 181:276-7 (In German).

7. Cashwell LF Jr, Holleman IL, Weaver RG, van Rens $\mathrm{GH}$. Idiopathic true exfoliation of the lens capsule. Ophthalmology. 1989;96:348-51.

8. Asakage $\mathrm{H}$, Ijichi $\mathrm{H}$, Ishiwata $\mathrm{T}$, et al. Report of two cases with idiopathic true exfoliation of lens capsule-histopathological and electron microscopical study. Nippon ganka gakkai zassi (J Jpn ophthalmol Soc). 1994;98:664-71.

9. Hwang YS, Chang SHL. Ultrasound biomicroscopy of capsular delamination (true exfoliation) of the crystalline lens. Chang Gung Med J. 2003;26: 930-2.

10. Karp CL, Fazio JR, Culbertson WW, Green WR. True exfoliation of the lens capsule. Arch Ophthalmol. 1999;117:1078-80.

11. Pereira NM, Dev A, Aravind H. Herniation of the anterior lens capsule. Ind J Ophthalmol. 2007;55: 228-30.

12. Oharazawa $H$, Suzuki $H$, Matsui $H$, Shiwa $T$, Takahashi $H$, Ohara K. Two cases of true exfoliation of the lens capsule after cataract surgery. J Nippon Med Sch. 2007;74:55-60.

13. Kulkarni AR, Al-Ibrahim J, Haider S, Elsherbiny S, Scott R. Phacoemulsification in true exfoliation of the lens capsule: a case series. Eye. 2007;21:835-7.

14. Anderson IL, van Bockxmeer FM. True exfoliation of the lens capsule: a clinicopathologic report. Aust NZ J Ophthalmol. 1985;13:343-7. 
15. Yamamoto N, Miyagawa A. True exfoliation of the lens capsule following uveitis. Graefes Arch Clin Exp Ophthalmol. 2000;238:1009-10.

16. Küchle M, Iliff WJ, Green WR. Combined true exfoliation and pseudoexfoliation of the anterior lens capsule. Klin Monatsbl Augenheilkd. 1996; 208:127-9.

17. Dvorak-Theobald G. Pseudoexfoliation of the lens capsule: relation to true exfoliation of the lens capsule as reported in the literature, and role in the production of glaucoma capsulocuticulare. Trans Am Ophthalmol Soc. 1953;51:385-407.

18. Resnikoff S, Filliard G, Dell'Aquila B. Climatic droplet keratopathy, exfoliation syndrome and cataract. Br J Ophthalmol. 1991;75:734-6.

19. Taylor HR. The environment and the lens. Br J Ophthalmol. 1980;64:303-10.
20. Naumann G, Schlotzer-Schrehardt U, Kuchle M. Pseudoexfoliation syndrome for the comprehensive ophthalmologist. Ophthalmology. 1998;105:951-68.

21. Scholotzer-Schrehardt U, Kuchle M, Naumann GOH. Electron-microscopic identification of pseudoexfoliation material in extrabulbar tissue. Arch Ophthalmol. 1991;109:565-70.

22. Seland JH. Ultrastructural changes in the normal human lens capsule from birth to old age. Acta Ophthalmol (Copenh). 1974;52:688-706.

23. Bleckmann H, Khodadadyan C, Schnoy N. Light and electron microscopy of the human, anterior cataract capsule. Fortschr Ophthalmol. 1989;86:556-60.

24. Ruotsalainen J, Tarkkanen A. Capsule thickness of cataractous lenses with and without exfoliation syndrome. Acta Ophthalmol (Copenh). 1987;65: 444-9. 